the neighboring muscles were so universally adherent. Compression under a gauze bandage was now applied. The wound healed rapidly, the greater part by first intention, with very little traumatic fever or discharge from the wound. The patient was shown in the clinic March 6th, ready to return home.

The temperature usually varied from $98.6^{\circ}$ to $100.4^{\circ} \mathrm{F}$., never exceeding $104^{\circ}$. The tumor, on examination, proved to be, as was supposed, an enchondroma, bluish-white, pearly, and elastic, being ossified in numerous isolated spots, as large as kernels of corn, scattered throughout the mass. The weight was a fraction over nine pounds. The limb is now capable of considerable voluntary flexion and some adduction.

\title{
SHORT COMMUNICATIONS.
}

\section{THE TOURNIQUET IN TREATMENT OF FRACTURE OF THE PATELLA.}

BY R. B. ROOT, M. D., GEORGETOWN, MASS.

I wish to call the attention of the readers of the Joursal to a modification, and I think a great improvement, of Dr. Galloupe's excellent apparatus for fracture of the patella, described in the Journal of August 16, 1877.

I have lately treated a case of fracture of the patella in an old man seventy-seven years of age, and I found that however nicely I might place the adhesive straps around the knee they would get loose in a day or two, necessitating their reapplication. And besides beconing loose they caused blisters to form the whole distance across the knee. Just here I happened to ihink of my tourniquet, and I found myself master of the situation, for by placing the screw on the outer side of the leg next to the splint, and making a "figure eight" turn, I had the fracture under perfect control. I could now adjust my pressure as the case required, and as the acute synovitis subsided a single turn or two of the screw brought all the pressure desirable. With the use of the tourniquet $I$ see no necessity for the long adhesive straps applied above and below the knee longitudinally, as it is simply necessary to sew the buckle to the strap of the tourniquet above the fracture, and the strip of cloth that goes through the buckle can just as well be sewed to the strap of the tourniquet below the fracture. I think any one trying this modification of Dr. Galloupe's apparatus will be surprised to find how much the tourniquet simplifies and makes easy what has heretofore been a difficult fracture to treat.

\section{GUM CUTTING AGAIN.}

\author{
BY JOHN YALE, M. D., WARE, MAS8.
}

Amone the many able and interesting articles contributed to the Journal by the late Prof. C. E. Buckingham was one on the propriety and usefulness of the operation of cutting the gums of children in appropriate conditions. Some time previously the question had been asked, derisively, Who cuts gums? A very decided answer, with reasons, was made by a correspondent, E. T. W., which seemed to settle the matter in its favor. At least my already written reply that $I$ did was committed to the waste basket, as $I$ thonght that enough had been said to convince the most skeptical. Grave doubts of its utility under any circumstances geem to exist.

There have been objections to the operation from excessive hemorrhage. Profensor Buckingham had never seen or known of such a case. Yet I have to confess to one thirty years ago. The child was eight months old, and the lower incisors were cut. The ooxing of blood continued till death, at the end of four days. In endearoring to find a cause for it $I$ remembered that instead of cutting directly on to the tooth the instrument glided inside, which may or may not explain its fatal result. To prevent any like occurrence I have always since cut them with the finger on one side and the thumb on the other, compressing the 